\title{
Effects of clomiphene citrate on seminal parameters in idiopathic oligospermia: a single blinded prospective randomized controlled trial
}

\author{
Apurba Mandal, Shibram Chattopadhyay*, Chandan Sasmal, Tapan Kumar Maiti, \\ Shritanu Bhattacharyya
}

Department of Obstetrics and Gynecology, Nil Ratan Sircar Medical College, Kolkata, West Bengal, India

Received: 27 August 2019

Revised: 03 November 2019

Accepted: 06 November 2019

*Correspondence:

Dr. Shibram Chattopadhyay,

E-mail: shibramchatt@gmail.com

Copyright: () the author(s), publisher and licensee Medip Academy. This is an open-access article distributed under the terms of the Creative Commons Attribution Non-Commercial License, which permits unrestricted non-commercial use, distribution, and reproduction in any medium, provided the original work is properly cited.

\begin{abstract}
Background: About $15 \%$ married couples face problem of infertility of which male factor is implicated in $20 \%$ of them. In about $30 \%$ infertile men no causative factor is found and the condition is termed "Idiopathic". They are often treated by empirical medications or Assisted Reproductive Technologies (ART) although success in few; our present study is carried on effects of clomephene citrate on seminal parameters in idiopathic oligospermia.

Methods: This single blinded prospective randomized controlled trial was conducted at the infertility clinic with 200 idiopathic oligospermic men (sperm count $<15$ millions/ $\mathrm{ml}$ of ejaculate) after fulfilling inclusion and exclusion criteria and were alternately allocated into two equal groups - "Group C" receiving clomephene citrate tablets and " Group P" receiving placebo after concealment. Semen analysis data were collected at baseline and every month and three months of completion of treatment and were summarized by routine descriptive statistical analysis.

Results: The demographic characteristics like mean age is comparative in both groups but duration of infertility of $>2$ years is more in group $C$ than group $\mathrm{p}(4.3 \pm 3.06$ versus $4.1 \pm 2.57)$. The semen volume, spermatozoa count, sperm motility and not normal form are all increased after three months of treatment in group $\mathrm{C}$ as are biochemical parameters like total testosterone and serum FSH, $\mathrm{LH}$ and as also pregnancy rate (22\% versus $4 \%$ ).

Conclusions: This study showed clomiphene citrate treatment protocol is inexpensive, relatively safe and easy to administer and improves semen volume, sperm count and sperm motility but not sperm morphology by increasing serum testosterone, FSH and LH in male and resulting in improved pregnancy rate in female partners.
\end{abstract}

Keywords: Clomiphene citrate, Idiopathic oligospermia, Male factor infertility, Pregnancy rate, Semen analysis, Sperm count

\section{INTRODUCTION}

Infertility remains a serious socio- medical problem worldwide and is defined as inability to conceive after one year of unprotected intercourse by couples of reproductive age group. About $15 \%$ of married couples face the problem with male gander implicated in $20 \%$ of them. ${ }^{1}$ In fact male factor plays more role in the etiology of infertility. ${ }^{2}$ These male infertility factors are almost always defined by finding of an abnormal semen analysis according to WHO criteria, although other factors play a role even when the semen analyses are normal. ${ }^{3}$ In male dominant societies particularly where illiteracy and poverty are more prevalent like in our country, man hardly agree to get investigated for infertility. ${ }^{4}$ According to WHO criteria (2010), Normozoospermia is defined as an ejaculate with sperm concentration of $>20 \times 106$ spermatozoa $/ \mathrm{ml}$, progressive sperm motility of $>50 \%$ or 
at least $25 \%$ of spermatozoa with linear progressive motility and $\geq 30 \%$ morphologically normal spermatozoa. Oligozoospermia or oligospermia is defined when sperm concentration is $<15 \mathrm{million} / \mathrm{ml}$ or motility $<40 \%$ or normal form $<4 \% .^{5}$ In about $30 \%$ of infertile men no causative factor is found for their decrease in sperm concentration or quality by common clinical, instrumental or laboratory means, and the condition is termed "Idiopathic". ${ }^{6}$ They are often treated by varieties of empirical medications or assisted reproductive technologies (ART) although success in few. ${ }^{2}$ In this context authors intended to perform the present study on the "Effects of clomiphene citrate on seminal parameters in idiopathic oligospermia".

\section{METHODS}

This study was conducted at the infertility clinic in our department of gynecology and obstetrics at NRSMC, Kolkata for one year between January 2017 to December, 2017 with 200 idiopathic oligospermic men (sperm count $<15 \mathrm{million} / \mathrm{ml}$ of ejaculate ) after fulfilling the inclusion criteria (healthy males 20-45 years of age marrying for $>$ 1 year with no issue giving informed written consent who were willing for treatment for 3 months with monthly follow-up and semen examination, serum testosterone (total), FSH and LH estimation and no past history of renal, hepatic or any other chronic illness like chronic sinusitis) and the exclusion criteria (azoospermia, obesity, male reproductive accessory gland infections, any recent medical or surgical illness, hypertension, oligospermia of definitive pathology, ejaculatory and erectile dysfunctions). Institutional Ethical Committee permission was taken. They were alternatively allocated into two equal groups - "Group C" receiving clomiphene citrate tablets $25 \mathrm{mg} /$ day for 25 days with 5 days rest for 3 months and "Group P" receiving placebo after, concealment. Data were collected for this single blinded prospective randomized controlled trial at baseline, every month during treatment and after completion of 3 months of treatment from subjects of both the groups. Semen samples were collected from subjects by masturbation following strict abstinence of 3 days from intercourse with a clean sterile wide mouthed jar of $20 \mathrm{ml}$ and analyses were performed within an hour of receiving the samples for semen volume, semen density, motility and morphology according to the WHO protocol: semen volume was measured directly on a graduated pipette after giving 20-30 minutes for liquefaction; sperm density was determined by using haemocytometer (Neubauer counting chamber); the percentage of mobile spermatozoa was taken as the proportion of progressive spermatozoa moving either slowly or rapidly relative to the hundred successive sperms under microscope. Two samples of $5 \mathrm{ml}$ blood were taken from antecubital vein from each subject before administration of first dose of clomiphene citrate and at the end of each month 24 hours after the last dose and analyzed by using standard ELISA method at the department of biochemistry at NRSMCH, Kolkata. Effects of clomiphene citrate were measured by comparing the changes in above parameters in the two groups. Pregnancies were documented in those patients who conceived during the three months of therapy using urinary rapid-kit test (Nischay kit supplied by the dept. of Health and Family Welfare, Govt. of India).

\section{Statistical analysis}

The sample size was calculated by taking $\alpha$ - error as 0.05 with power of $80 \%$ ( $\beta$ - error as 0.2 ) and degree of variance of mean of $15 \%$ of primary outcome measures with standard statistical formula showing the minimum number to be 70 in each group. All statistical analyses were carried out using Statistica version 6 (Tusla, Oklahoma: Statsoft Inc., 2001), www.medcalc.org and Graph Pad Prism Version 5 (San Diego, California: Graph Pad Software Inc., 2007) software's. Data had been summarized by routine descriptive statistics. Mean values of semen parameters and hormonal levels were compared between two groups using Student's unpaired t-test. Non- parametric numerical variables were compared between groups by Mann - Whitney U test. For intragroup comparison of changes of semen and hormonal parameters Repeated Measures ANOVA was employed followed by Tukey's Multiple Comparison Test where Repeated Measure ANOVA returned p- value $<0.05$. Fishers exact test was used to compare pregnancy rate between the two groups. Analyses were 2 - tailed and $\mathrm{p}$ - value of $<0.05$ was considered as statistically significant.

\section{RESULTS}

It is seen from the data through Table 1 (demographic variables), Table 2 (primary outcome measures) and (secondary outcome measures) depicted below that mean age in both groups are comparable $(29.9 \pm 8.64$ in group $\mathrm{C}$ versus $28.7 \pm 7.25$ in group $\mathrm{P}$ ) but the duration of infertility of $>2$ years is more in group $\mathrm{C}$ than group $\mathrm{P}$ $(4.3 \pm 3.06$ versus $4.1 \pm 2.57)$.

Table 1: Demographic variables, (age groups in infertile couples and duration of infertility in infertile couples).

\begin{tabular}{|c|c|c|c|}
\hline Characteristics & & & p-value \\
\hline Age (years) & $\begin{array}{l}\text { Group C } \\
(\%) \\
(\mathbf{n}=\mathbf{1 0 0})\end{array}$ & $\begin{array}{l}\text { Group P } \\
(\%) \\
(\mathbf{n}=\mathbf{1 0 0})\end{array}$ & \\
\hline $21-25$ & 32 & 34 & \multirow{5}{*}{$\begin{array}{l}0.2887 ; 95 \% \\
\text { CI }(-3.4242 \\
\text { to } 1.0242), \\
t=-1.064\end{array}$} \\
\hline $26-30$ & 28 & 40 & \\
\hline $31-35$ & 26 & 16 & \\
\hline $36-40$ & 14 & 10 & \\
\hline Mean \pm SD & $29.9 \pm 8.64$ & $28.7 \pm 7.25$ & \\
\hline \multicolumn{4}{|c|}{ Duration of infertility (years) } \\
\hline$\leq 2$ & 32 & 52 & \multirow{4}{*}{$\begin{array}{l}0.6173 ; 95 \% \\
\text { CI }(-0.9880 \\
\text { to } 0.5880), \\
t=-0.500\end{array}$} \\
\hline $3-5$ & 56 & 42 & \\
\hline$\geq 6$ & 12 & 6 & \\
\hline Mean \pm SD & $4.3 \pm 3.06$ & $4.1 \pm 2.57$ & \\
\hline
\end{tabular}


Table 2: Outcomes.

\begin{tabular}{|c|c|c|c|c|c|}
\hline Characteristics & $\begin{array}{l}\text { Group C } \\
(\text { Mean } \pm \text { SD })\end{array}$ & $\begin{array}{l}\text { Group P } \\
(\text { Mean } \pm \text { SD })\end{array}$ & p-value* & \multicolumn{2}{|c|}{ Within group p-value $* *$} \\
\hline \multicolumn{4}{|c|}{ Primary outcomes } & Group C & Group P \\
\hline \multicolumn{6}{|l|}{ Semen volume (ml) } \\
\hline Baseline & $2.4 \pm 0.57$ & $2.2 \pm 0.57$ & 0.101 & \multirow{4}{*}{$<0.001$} & \multirow{4}{*}{0.078} \\
\hline After 1 month & $2.6 \pm 0.57$ & $2.2 \pm 0.49$ & 0.003 & & \\
\hline After 2 months & $2.7 \pm 0.51$ & $2.3 \pm 0.47$ & 0.000 & & \\
\hline After 3 months & $3.1 \pm 0.58$ & $2.3 \pm 0.50$ & 0.000 & & \\
\hline \multicolumn{6}{|c|}{ Spermatozoa count $(\mathrm{mil} / \mathrm{ml})$} \\
\hline Baseline & $11.2 \pm 2.64$ & $11.4 \pm 4.02$ & 0.747 & \multirow{4}{*}{$<0.001$} & \multirow{4}{*}{$<0.001$} \\
\hline After 1 month & $13.8 \pm 3.99$ & $12.1 \pm 3.99$ & 0.036 & & \\
\hline After 2 months & $17.3 \pm 5.88$ & $12.9 \pm 4.21$ & 0.000 & & \\
\hline After 3 months & $25.6 \pm 8.89$ & $14.2 \pm 5.50$ & 0.000 & & \\
\hline \multicolumn{6}{|l|}{ Sperm motility (\%) } \\
\hline Baseline & $46.7 \pm 9.74$ & $45.9 \pm 8.23$ & 0.666 & \multirow{4}{*}{$<0.001$} & \multirow{4}{*}{$<0.001$} \\
\hline After 1 month & $48.9 \pm 9.56$ & $47.1 \pm 8.31$ & 0.318 & & \\
\hline After 2 months & $50.9 \pm 9.56$ & $47.9 \pm 8.33$ & 0.100 & & \\
\hline After 3 months & $53.8 \pm 10.17$ & $49.0 \pm 8.05$ & 0.000 & & \\
\hline \multicolumn{6}{|c|}{ Sperm morphology - normal form $(\%)$} \\
\hline Baseline & $33.0 \pm 14.66$ & $35.0 \pm 13.98$ & 0.474 & \multirow{4}{*}{$<0.001$} & \multirow{4}{*}{$<0.001$} \\
\hline After 1 month & $34.1 \pm 14.68$ & $35.5 \pm 13.80$ & 0.605 & & \\
\hline After 2 months & $35.1 \pm 14.77$ & $36.2 \pm 13.81$ & 0.706 & & \\
\hline After 3 months & $36.6 \pm 15.11$ & $37.1 \pm 13.67$ & 0.873 & & \\
\hline \multicolumn{6}{|c|}{ Secondary outcomes } \\
\hline \multicolumn{6}{|c|}{ Serum testosterone (ng/ml) } \\
\hline Baseline & $4.1 \pm 0.75$ & $4.1 \pm 0.70$ & 0.701 & \multirow{4}{*}{$<0.001$} & \multirow{4}{*}{$<0.001$} \\
\hline After 1 month & $4.4 \pm 0.76$ & $4.2 \pm 0.72$ & 0.245 & & \\
\hline After 2 months & $4.9 \pm 0.69$ & $4.2 \pm 0.73$ & 0.000 & & \\
\hline After 3 months & $5.6 \pm 0.81$ & $4.3 \pm 0.73$ & 0.000 & & \\
\hline \multicolumn{6}{|l|}{ Serum FSH (mIU/ml) } \\
\hline Baseline & $5.6 \pm 1.33$ & $5.3 \pm 0.80$ & 0.139 & \multirow{4}{*}{$<0.001$} & \multirow{4}{*}{$<0.001$} \\
\hline After 1 month & $6.2 \pm 1.30$ & $5.4 \pm 0.77$ & 0.000 & & \\
\hline After 2 months & $6.7 \pm 1.35$ & $5.5 \pm 0.77$ & 0.000 & & \\
\hline After 3 months & $7.6 \pm 1.58$ & $5.6 \pm 0.79$ & 0.000 & & \\
\hline \multicolumn{6}{|l|}{ Serum LH (mIU/ml) } \\
\hline Baseline & $5.7 \pm 1.10$ & $5.8 \pm 1.30$ & 0.691 & \multirow{4}{*}{$<0.001$} & \multirow{4}{*}{$<0.001$} \\
\hline After 1 month & $6.3 \pm 0.97$ & $5.8 \pm 1.26$ & 0.029 & & \\
\hline After 2 months & $7.2 \pm 0.95$ & $5.9 \pm 1.20$ & 0.000 & & \\
\hline After 3 months & $8.1 \pm 1.00$ & $6.0 \pm 1.21$ & 0.000 & & \\
\hline Pregnancy rate after 3 & onths of trea & ment & & & \\
\hline $\begin{array}{l}\text { Positive urinary kit test } \\
(\%)\end{array}$ & 22 & 4 & $\begin{array}{l}0.0002 ; 95 \\
14.252 ; \mathrm{DF}\end{array}$ & $27.3912)$ & quared $* * * *=$ \\
\hline Side effects of clomiph & e citrate & & & & \\
\hline Nausea & 5 & 1 & & & \\
\hline Hypertension & 3 & 1 & $0.0981(95$ & $\begin{array}{l}.2297) 0.31 \\
* * * * .024\end{array}$ & $\%$ Cl: - \\
\hline Blurred vision & 2 & 0 & $1(\mathrm{CI} * * * * *)$ & $0.000)$ & $4,2-1.000)$ \\
\hline Psychotic reaction & 1 & 0 & the & & \\
\hline
\end{tabular}

The semen volume, spermatozoa counts, sperm motility and normal sperm are all increased in group $\mathrm{C}$ than group
$\mathrm{P}$ after 3 months of treatment as depicted in Table 2.

Total testosterone level, serum FSH and $\mathrm{LH}$ are all 
increased also; Pregnancy rate with positive urine for pregnancy test are significantly more in group $\mathrm{C}$ than group P $(22 \%$ versus $4 \%)$ while side effects occurred slightly more in group $\mathrm{C}$ as observed in Table 2.

\section{DISCUSSION}

Inability to conceive in an eligible couple at their starting of married life is a social and psychological stigma still today in modern days and blaming female partner ignoring male counterpart has resulted in higher treatment cost to overcome. ${ }^{7}$ Clomiphene citrate, 1-[p(beta-diethylaminoethoxy)phenyl] $\quad-1,2$ diphenyl chloroethylene, is an orally active non-steroidal agent distantly related to diethylstilbestrol and it acts by stimulating pituitary gonadotrophin release and increased testosterone released by the Leydig cells. ${ }^{8,9}$ Many doses and protocols of using clomiphene citrate are reported while $25 \mathrm{mg}$ daily for 25 days followed by a drug free interval of 5 days for 3 months is studied 10. Increase endogenous testosterone is related to seminal vesicle functions. Clomiphene citrate also stimulates sertoli cells resulting in more spermatocytes. ${ }^{11,12}$ Like our study, Fuse $\mathrm{H}$ et al; Simantini et al; Zaman et al; Moradi et al, have shown increase in semen volume, sperm count and motility whereas Ronnberg et al; Ghanem et al showed diminished motility and no improvement in morphology. ${ }^{13-17}$ Increase in the serum testosterone, FSH and LH levels after treatment are corroborated well in studies by Fuse $\mathrm{H}$ et al; Zaman et al; AT Guay et al and Da Ros CT et al. ${ }^{13,15,19,20}$ Higher pregnancy rates in group $\mathrm{C}$ than in group $\mathrm{P}$ are also observed in studies by Ronnberg L et al, and Wang et al. ${ }^{17,21}$ The minor side effects of clomiphene citrate occurred during treatment and are subsided with time and no patient needed drug discontinuation. Siddiq et al also reported side effects are usually mild and occur in less than $5 \%$ of patients. ${ }^{22}$

\section{CONCLUSION}

Patients with idiopathic oligospermia not only are frustrated by having no explanation for their problem but also are surprised by the scarcity of effective medical treatments to improve upon the production and quality of their sperm. This study shows clomiphene citrate improves semen volume, sperm count and sperm motility but not sperm morphology by increasing serum testosterone, FSH and LH with improved pregnancy rate in female partners. This treatment protocol is inexpensive, relatively safe, easily accepted and easy to administer. Although clomiphene citrate is used as first line therapy in idiopathic oligospermia for many years, its effectiveness is not yet well established. Further clinical studies with large number of patients with a longer follow- up period are needed on a multicentric basis to substantiate in Indian perspective.

Funding: No funding sources Conflict of interest: None declared
Ethical approval: The study was approved by the Institutional Ethics Committee

\section{REFERENCES}

1. Rubenstein JN, Brannigan RE. Infertility, Male. e Medicine. 2008:1-31. Available at: www. emedicine.com/med/TOPIC 1167. HTM.

2. Sigman M, Jarow JP. Male Infertility. In: Wein AJ, Kavoussi LR, Novick AC, Partin AW, Peters CA, eds. Campbell - Walsh Urology. Vol 1. Philadelphia: Saunders 2007: 609-53.

3. Jalbani MH, Rikhasor RM, Pathai S, Solangi GA, Baloch R. Causes of Azoospermia in infertile men. Original Paper. 2001;7(2):36-8.

4. Rikhasor RM, Pathai S, Jalbani MH, Pirzado ZA, Abbasi SA. Semen analysis of infertile men and plasma levels of LH, FSH and Testosterone in oligospermia. Original Paper. 2001;7(2):30-2.

5. World Health Organisation. 2010. Laboratory manual for the examination and processing of human semen. Available at: http//whqlibdoc.who.int/publications/2010/97892415 47789 - eng.pdf.

6. Cavallini G. Male idiopathic oligoasthenoteratozoospermia. Asian J Androl. 2006;8(2):143-57.

7. Etiology of infertility study of 6009 infertile couples over 17 years. JOGI R Rajan. 1990;40(3):400-6.

8. Akin JW. The use of clomiphene citrate in the treatment of azoospermia secondary to incomplete androgen resistance. Fertil Steril. 1993;59(1):223-4.

9. Hussein A, Ozgok Y, Ross L, Neiderberger C. Clomiphene administration for cases of nonobstructive azoospermia: A multicenter study. Elsevier J Androl. 2005;26(6):787-91.

10. Pusch HH, Haas J, Purstner P. Results of low dose treatment of oligospermia with clomiphene citrate. Androl. 1986; 18:561.

11. Skinner MK, Griwold MD. Sertoli cells synthesize and secrete transferrin-like protein. J Biol Chem 1980;255(20):9523-25.

12. Gonzales GF. Function of seminal vesicles and their role in male infertility. Asian $\mathrm{J}$ Androl. 2001;3(4):251-8.

13. Fuse H, Ohta S, Sakamoto M, Katayama T. Changes in seminal plasma transferrin concentration following administration of clomiphene citrate. Arch Androl. 1993;31(2):139-45.

14. Patankar SS, Kaore SB, Sawane MV, Mishra NV, Deshkari AM. Effects of clomiphene citrate on sperm density in male partners of infertile couples. Indian J Physiol Pharmacol. 2007;51(2):195-8.

15. Zaman S, Zulfikar S, Khan S. Evaluation of effects of clomiphene citrate on serum testosterone FSH levels and seminal parameters in idiopathic oligospermia. Biomedica. 2009;25:48-51.

16. Moradi M, Moradi A, Alemi M, Ahmadnia H. Safety and efficacy of clomiphene citrate and L- carnitine in 
idiopathic male infertility: a comparative study. Urol J. 2010;7:188-93.

17. Ronnberg L. The effect of clomiphene citrate on different sperm parameters and serum hormone levels in preselected infertile men: a controlled double blind cross-over study. Int $\mathbf{J}$ Androl. 1980;3:479-86.

18. Ghanem H, Shaeer O, El-Segini A. Combination of clomiphene citrate and antioxidant therapy for idiopathic male infertility: a randomized controlled trial. Fertil Steril. 2010;93:2232-5.

19. Gray AT, Jacobson J, Parez JB, Hodge MB, Velasquez E. Clomiphene increases free testosterone levels in men with both secondary hypogonadism and erectile dysfunction: who does and does not benefit? Int J Impot Res. 2003;15:156-65.

20. Da Ros CT, Averbeck MA. Twenty-five milligrams of clomiphene citrate presents positive effect on treatment of male testosterone deficiency - a prospective study. Int Braz J Urol. 2012;38:512-8.

21. Wang C, Chan C, Wong K, Yeung K. Comparison of the effectiveness of placebo, clomiphene citrate, mesterolone, pentoxyfylline and testosterone rebound therapy for the treatment of idiopathic oligospermia. Fertil Steril. 1983;4:358-65.

22. Siddiq FM, Sigman M. A new look at the management of infertility. Urol Clin North Am. 2002;29(4):949-63.

Cite this article as: Mandal A, Chattopadhyay $\mathrm{S}$, Sasmal C, Maiti TK, Bhattacharyya S. Effects of clomiphene citrate on seminal parameters in idiopathic oligospermia: a single blinded prospective randomized controlled trial. Int J Reprod Contracept Obstet Gynecol 2020;9:94-8. 